\title{
Rice Hull-Derived Silica: Applications in Portland Cement and
}

\section{Mullite Whiskers}

\author{
M.F. de Souza ${ }^{a}$, P.S. Batista ${ }^{a}$, I. Regiani ${ }^{a}$, J.B.L.Liborio ${ }^{b}$, D.P.F. de Souza ${ }^{c} *$ \\ ${ }^{\mathrm{a}}$ Departamento de Física e Ciência de Materiais, \\ Universidade de São Paulo, São Carlos - SP, Brazil \\ ${ }^{\mathrm{b}}$ Laboratório de Engenharia Civil, Departamento de Arquitetura, Escola de \\ Engenharia de São Carlos, Universidade de São Paulo, São Carlos - SP, Brazil \\ ${ }^{\mathrm{c}}$ Departamento de Engenharia de Materiais, Universidade Federal de São Carlos, \\ São Carlos - SP, Brazil
}

Received: July 2, 1999 Revised: February 28, 2000

\begin{abstract}
Silica was extracted from rice hulls by three processing routes, starting with acid treatment followed by burning and milling. The amorphous white silica powder showed a surface area of 260 to $480 \mathrm{~m}^{2} / \mathrm{g}$, purity above $99 \%$ and average particle size of 2.0 to $0.6 \mathrm{~mm}$. This silica is suitable for the preparation of mullite whiskers employing the rare earth aluminosilicate glass technique. Due to its highly pozzolanic reaction, this prepared silica is used as an additive in high performance concrete.
\end{abstract}

Keywords: silica, concrete, mullite, rice hulls

\section{Introduction}

Rice hulls and plants have an unusually high silica content ${ }^{1}$. The concentration of substances found in the dry hull and plant depends on the type of soil, plant variety and climate, among other parameters ${ }^{1}$. Silica concentrations in the dry hull can be as high as $21.5 \mathrm{wt} \%^{1}$ and $12 \mathrm{wt} \%$ in the dry leaves ${ }^{2}$. The total concentration of other inorganic oxides in relation to the silica content is close to $5 \mathrm{wt} \%$. Hulls are almost $20 \mathrm{wt} \%$ of the dry seeds; thus, the total amount of silica in rice hulls can be as high as $4 \mathrm{wt} \%$ of a rice $\mathrm{crop}^{2}$. The annual worldwide output of rice hulls is approximately 80 million tons, which corresponds to 3.2 million tons of silica ${ }^{3}$. This potential for rice hull-derived silica production could be economically advantageous if the extracted silica were a high quality product insofar as surface area, particle size and purity are concerned. Rice production in Brazil is 10 million tons/year and most of the hulls are burned. The thermal energy requirements of rice processors, high transportation costs owing to the low packing density of hulls, and the lack of other significant uses for this agricultural residue make burning the most common practice. Burning produces a dark residue that contains almost $15 \mathrm{wt} \%$ of carbon ${ }^{4}$. This residue, known as rice hull ash, is extremely hazardous to the environment and to humans. Moreover, when this ash is added to mixtures containing liquids such as water, the carbon content strongly affects the rheology of the suspension. Further heating of the ash to eliminate residual carbon produces $\approx 95$ $\mathrm{wt} \%$ pure silica with $\approx 10.0 \mathrm{~m}^{2} / \mathrm{g}$ specific surface area ${ }^{4}$ and particle sizes above $20 \mu \mathrm{m}$, resulting in a product of low economic value. The main impurities in silica obtained by this route are potassium, calcium, magnesium and sodium ${ }^{4}$. Many processes have been proposed for the productive use of large residues of hulls ${ }^{5}$. Several researchers have produced silicon carbide ${ }^{6-8}$ and silicon nitride ${ }^{9-11}$, taking advantage of the silica distributed in the organic structure of the hulls.

Yoshida et al. ${ }^{12}$ found that silica is distributed mainly in the outer layer of the hull, although other parts of the plant where water losses are high also contain silica. These authors have reported that silica gel is the most prevalent form of silicon in rice plants. Crystalline silica has been found in several plants ${ }^{13}$, but Lanning found it to be amorphous in rice plants and hulls ${ }^{14}$. Silica distribution among the three main organic components, i.e., cellulose, lignin and hemicellulose, in the hull's structure was studied by Sheng-Lieh ${ }^{15}$, who found that, after extracting lignin using concentrated acetic acid, the silicon content in the hull remained unchanged, leading to the conclusion that silica

*dulcina@power.ufscar.br 
was bound to the polysaccharide part of the hull, cellulose and hemicellulose.

Silica extraction from rice hulls has been extensively investigated by several authors. James and Rao ${ }^{16}$ studied the thermal decomposition of untreated rice hulls and found that lignin decomposes at higher temperatures than cellulose does; however, the surface area and particle size of the silica thus obtained were not determined. Bartha and Huppertz ${ }^{17}$ found that the microstructure of silica released from rice hulls by hydrochloric acid treatment is similar to that obtained by thermal decomposition of the hull. Hamad and Khattab $^{18}$ studied the X-Ray Diffraction, XRD, of silica obtained from untreated hulls by thermal decomposition under three different conditions and found that thermal treatment below $800{ }^{\circ} \mathrm{C}$ results in amorphous silica. The first systematic study on acid rice hull treatment before its thermal decomposition was reported by Amick ${ }^{19}$, whose objective was to produce solar grade silicon. By treating silica obtained by thermal decomposition of untreated hulls in an aqueous 1:1 $\mathrm{HCl}$ solution, Amick ${ }^{19}$ found that it was possible to reduce the level of impurity from $5 \mathrm{wt} \%$ to 0.15 wt $\%$. Since the author was interested in silicon rather than in silica, however, silica particle size and specific area were not measured. James and $\mathrm{RaO}^{20}$ studied burned untreated rice hulls, followed by hydrochloric acid leaching of silica. They found that acid treatment produces silica with a very low impurity content $(0.035 \mathrm{wt} \%)$. The maximum specific surface area reported for carbon-free silica was around 150 $\mathrm{m}^{2} / \mathrm{g}$. The ultimate crystallite size was estimated by X-ray diffraction $(X R D)$ pattern to be $\approx 5.0 \mathrm{~nm}$, although particle size was not reported. More recently, Real et al. ${ }^{21}$ reported on silica preparation by thermal decomposition of $\mathrm{HCl}$ treated rice hulls. These authors successfully produced high purity silica $(99.4 \%)$ with high surface area $\left(260 \mathrm{~m}^{2} / \mathrm{g}\right)$ by thermally decomposing acid treated rice hulls at $600{ }^{\circ} \mathrm{C}$. Crystallite sizes, estimated by transmission electron microscopy (TEM), were found to be a few nanometers in size. Particle size distribution, however, was not reported.

This paper reports on silica prepared from acid-treated rice hulls. The work focused on the use of silica in the production of mullite whiskers and cementitious materials, in which the reactivity and particle size of silica are important features.

\section{Experimental}

\subsection{Silica}

Dry rice hulls from plantations in the Paraíba river valley, state of São Paulo, Brazil, were acid treated, washed in water and burned by three different procedures: A) Treatment with a $3.0 \mathrm{wt} \%$ sulfuric acid solution at $150{ }^{\circ} \mathrm{C}$ and $7.0 \mathrm{~atm}$ pressure for $1.0 \mathrm{~h}$, followed by washing with tap water at room temperature. The acid treatment was carried out inside a high-pressure vessel with corrosion- protected lining. A muffle oven was used to burn rice hulls at $550{ }^{\circ} \mathrm{C}$ for two hours in air; B) Treatment with $20 \mathrm{vol} \%$ hydrochloric acid solution for $24 \mathrm{~h}$, followed by a $20 \mathrm{vol} \%$ sulfuric acid solution for $24 \mathrm{~h}$. Both treatments were done by boiling the solution under atmospheric pressure, followed by washing with distilled water. The hulls were then heated at $550{ }^{\circ} \mathrm{C}$ for $2.0 \mathrm{~h}$; C) The rice hulls, acid treated and washed according to process $\mathrm{A}$, were subjected to lignin extraction through refluxing in glacial acetic acid, followed by washing in distilled water at room temperature and then burning at $500{ }^{\circ} \mathrm{C}$ for $2.0 \mathrm{~h}$. In each process, the silica was desegregated by ball milling in water with $0.5 \mathrm{~cm}$ zirconia balls. The silica was named according to the processing route, i.e., silica A, B, and C. A commercial silica, dubbed D, was also used in this study for purposes of comparison. The powders and powder suspensions were chemically characterized by Inductively Coupled Plasma Atomic Emission Spectroscopy (ICP), while the surface area was analyzed by the BET method, particle size distribution determined by the sedimentation technique and crystallographic structure by XRD.

\subsection{Mullite whiskers}

The starting materials used for the preparation of mullite whiskers were the same as those used in a previous study for mullite preparation ${ }^{22}$ : silica produced by route B, aluminum hydroxide (purified aluminum hydroxide from the aluminum anodization process), and $99.9 \%$ pure yttrium oxide (Cerac, USA). Milling and mixing were done for $24 \mathrm{~h}$ using $0.5 \mathrm{~cm}$ zirconia balls (Tosoh, Japan) in high density polyethylene jars. The composition was adjusted to produce $3.0 \mathrm{~mol} \% \mathrm{Y}_{2} \mathrm{O}_{3}$ doped $3: 2 \mathrm{Al}_{2} \mathrm{O}_{3} / \mathrm{SiO}_{2}$. The powder suspension turned into a thick diphasic gel by adding nitric acid and was slowly dried at $60{ }^{\circ} \mathrm{C}$. The resulting material was heated to $200{ }^{\circ} \mathrm{C}$, crushed in an agate mortar and calcined at $1000{ }^{\circ} \mathrm{C}$ for $2 \mathrm{~h}$. The powder was milled in acetone, with the addition of $2.0 \mathrm{wt} \%$ polyvinilbutiral, in a high density polyethylene jar using $0.5 \mathrm{~cm}$ zirconia balls. Pellets were produced by isostatic pressing at $200 \mathrm{MPa}$ and fired at $1600{ }^{\circ} \mathrm{C}$ for $3 \mathrm{~h}$ in air.

Aluminum hydroxide was prepared from the reaction between a diluted aluminum sulfate solution, derived from aluminum anodization, with a diluted sodium hydroxide solution and flocculated by polyacrilamide. The floccules were washed in water until the sulfate test by silver nitrate solution indicated a negative reading. The average particle size of the aluminum hydroxide was found to be $50 \mathrm{~nm}$.

\subsection{Addition of pozzolana to cement}

Silica A was added to Portland cement to study its effects on the compressive strength of cured cement bodies. The degree of reaction between silica and calcium hydroxide, the so-called pozzolanic character of silica, was previously measured by the Chapelle-modified procedure ${ }^{23,24}$, 
by which $1.0 \mathrm{~g}$ of silica and $1.0 \mathrm{~g}$ of calcium oxide were added to $200 \mathrm{~mL}$ of $\mathrm{CO}_{2}$ free water in an Erlenmeyer flask. The suspension was agitated at $100{ }^{\circ} \mathrm{C}$ for $16 \mathrm{~h}$ in a closed plastic bottle. After cooling, care was taken to dissolve the nonreacted $\mathrm{Ca}(\mathrm{OH})_{2}$ completely in water before filtering. The results are expressed as the amount of reacted $\mathrm{CaO}$. The free calcium hydroxide was dosed with a $0.01 \mathrm{~N} \mathrm{HCl}$ solution. Specimens for compression tests were prepared as follows: silica in an aqueous suspension, stabilized by sulfo-melanin surfactant, was added to cement (CPV ARI RS) in a planetary mixer. All the final prepared mixtures had $47.0 \mathrm{wt} \%$ of water and $1.2 \mathrm{wt} \%$ surfactant in relation to the cement. The test specimens were cured in a chamber at $23{ }^{\circ} \mathrm{C}$ and $95 \%$ humidity for $3,7,14$ and 28 days. The batch compositions were prepared as follows: $\mathrm{M}$ ) cement without added silica; $\mathrm{N}$ ) cement with a $5.0 \mathrm{wt} \%$ addition of commercial microsilica (Elkem; Brazil), P) cement with a $10.0 \mathrm{wt} \%$ addition of commercial microsilica; O) cement with a $5.0 \mathrm{wt} \%$ addition of microsilica A.

\subsection{Results and Discussion}

\subsection{Silica}

White amorphous silica was produced by thermal decomposition of the rice hulls by the three above described preparation processes. The amorphous state of the silica obtained by procedure A is clearly shown by its XRD pattern, Fig. 1. The chemical composition, surface area, average particle size and reactivity with calcium hydroxide of silica produced by each of those procedures are shown in Tables 1 and 2.

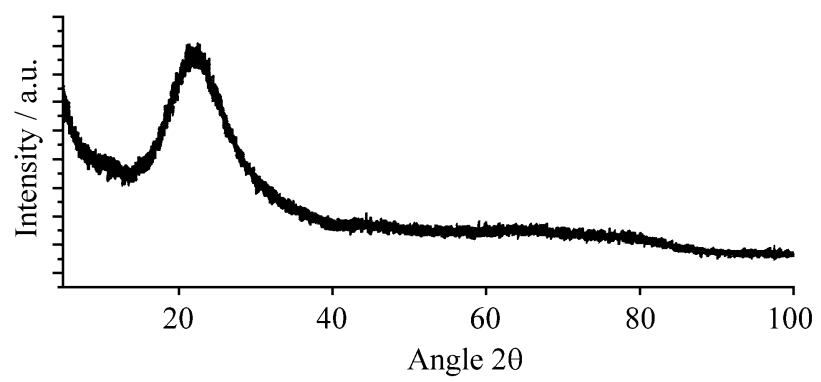

Figure 1. XRD pattern of silica extracted from rice hulls by burning at $500{ }^{\circ} \mathrm{C}$.

Table 1. Characteristics of the prepared silica and its pozzolanic reactivity.

\begin{tabular}{lcccc}
\hline $\begin{array}{l}\text { Proces. } \\
\text { Route }\end{array}$ & $\begin{array}{c}\text { Surface } \\
\text { Area }\left[\mathrm{m}^{2} / \mathrm{g}\right]\end{array}$ & $\begin{array}{c}\text { Average } \\
\text { particle size } \\
{[\mu \mathrm{m}]}\end{array}$ & $\begin{array}{c}\mathrm{SiO}_{2} \\
\text { concentration } \\
{[\mathrm{wt} \%]}\end{array}$ & $\begin{array}{c}\mathrm{CaO} \\
\text { reacted } \\
{[\%]}\end{array}$ \\
\hline A & 260 & 2.0 & 98.9 & 85 \\
B & 480 & 0.6 & 99.7 & 94 \\
C & 290 & 1.5 & 99.2 & 88 \\
\hline
\end{tabular}

Table 2. Silica ICP Chemical Analysis, wt \%.

\begin{tabular}{lccc}
\hline Compound & A & B & C \\
\hline $\mathrm{SiO}_{2}$ & 98.94 & 99.69 & 99.22 \\
$\mathrm{Fe}_{2} \mathrm{O}_{3}$ & 0.06 & 0.05 & 0.05 \\
$\mathrm{Al}_{2} \mathrm{O}_{3}$ & 0.08 & 0.06 & 0.08 \\
$\mathrm{TiO}_{2}$ & 0.01 & 0.01 & 0.01 \\
$\mathrm{MnO}_{2}$ & 0.001 & 0.001 & 0.001 \\
$\mathrm{MgO}$ & 0.05 & 0.03 & 0.03 \\
$\mathrm{Na} 2 \mathrm{O}$ & 0.01 & 0.01 & 0.01 \\
$\mathrm{CaO}$ & 0.75 & 0.05 & 0.50 \\
$\mathrm{~K} 2 \mathrm{O}$ & 0.10 & 0.10 & 0.10 \\
\hline
\end{tabular}

Let us consider the well known relationship between particle size, D, and surface area, AE, of an ideal powder with spherical particles of the same size,

AE . D . $\rho=6$

where $\rho$ represents silica density and D represents particle diameter. Replacing D by the average particle diameter, $\mathrm{D}_{\mathrm{av}}$, of a real particle size distribution gave us a reasonable idea of the particle aggregation. Considering the above equation and $\mathrm{AE}=480 \mathrm{~m}^{2} / \mathrm{g}$ for silica $\mathrm{B}$, the calculated particle size was $5 \mathrm{~nm}$, while the measured average particle size was $600 \mathrm{~nm}$. Hence, silica powder particles are porous aggregates of nano sized ultimate particles. Real et al. ${ }^{20}$ had already reported similar results obtained by TEM. Impurities such as the alkalis and nano sized particles contribute to particle aggregation during burning of organic hull matter. The effect of acid treatment and leaching before burning is illustrated in Tables 1 and 2. To obtain particle sizes smaller than those reported here, organic matter must be burned at lower temperatures. An attractive approach to silica extraction, though not considered in this study, is to attack the organic substances, mainly cellulose and lignin, with fungi enzymes at room temperature ${ }^{25}$. Another possible approach is through chemical attack; however, undesirable chemical modifications of silica would occur if attacked by bases. The main organic substances in the hulls are cellulose, lignin and hemicelulose. The acid attack carried out in the first step of silica production of this study removed most of the inorganic impurities and hemicelulose, although no reduction in silica content, cellulose or lignin was observed. In procedure $\mathrm{C}$, almost $50 \%$ of the hull's lignin was dissolved in glacial acetic acid without any loss of silica, leading to the conclusion that silica is bound mainly to cellulose. A fungi attack on the cellulose would release the silica; however, lignin is strongly linked to cellulose in the hull, making a fungi attack difficult ${ }^{25}$. Nature has apparently provided the right combination of silica, cellulose and lignin to best protect 
the rice grain. Hitherto, burning is the best process to separate silica from the organic components in the rice hull $^{26}$ and, for that reason, particle aggregation will always occur.

Acid treatment and leaching are necessary steps to obtain pure, low average particle size and high surface area silica. The preparation of silica B shows the effect of removing impurities on the silica's surface area and purity, Tables 1 and 2. Alkaline oxides such as $\mathrm{K}_{2} \mathrm{O}$, the most abundant impurity in rice hulls, are known to react with silica to produce potassium silicate, thus resulting in bridging among the ultimate particles when the hull is burned. The higher surface area energy of nano sized ultimate particles also contributes to their aggregation under heating. The effect of reducing lignin content in the hulls before burning was well illustrated when silica $\mathrm{C}$ was obtained, allowing for a lower burning temperature over the same time interval. Burning temperatures and times largely depend on the burning technique. A significant decrease in burning time and temperature can be achieved in a rotating furnace, allowing for better access of oxygen to the hull.

\subsection{Aplications}

\section{2a. Mullite whiskers}

Low thermal expansion coefficient, chemical inertia and refractoriness (low deformation under stress at elevated temperatures) are the most important properties of pure mullite ${ }^{27}, 3 \mathrm{Al}_{2} \mathrm{O}_{3}: 2 \mathrm{SiO} 2$. To maintain its properties, a mullite ceramic body must be free of glass phases. Therefore, to prepare pure mullite, the glass modifiers, i.e., impurities such as potassium, must be removed from the rice hull. The same holds true for high quality mullite whiskers produced by the process described in this paper. Large amounts of

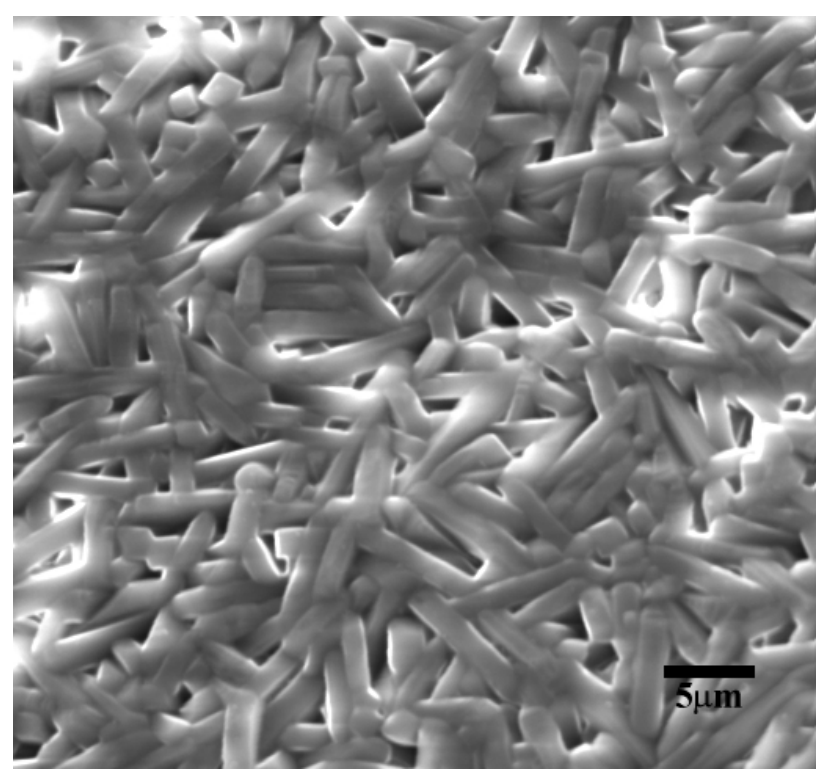

Figure 2. SEM microstructure of the external surface of a pellet of 3.0 mol\% $\mathrm{Y}_{2} \mathrm{O}_{3}$ doped 3:2 mullite composition fired at $1600{ }^{\circ} \mathrm{C}$ for $3.0 \mathrm{~h}$. almost pure mullite whiskers were obtained by firing 3.0 mol\% $\mathrm{Y}_{2} \mathrm{O}_{3}$ doped $3: 2 \mathrm{Al}_{2} \mathrm{O}_{3} / \mathrm{SiO}_{2}$ pellets at $1600{ }^{\circ} \mathrm{C}$ for 3.0 h, see Fig. 2. The SEM microstructure was taken from the surface of the pellet with no further preparation. It was found that whiskers grew all over the pellet's surface, i.e., on the external and internal voids, see Fig. 3. The XRD pattern taken from the pellet's external surface, Fig. 4, displays characteristic mullite peaks with preferential orientation of the whisker c-axis ${ }^{28}$ parallel to the pellet's surface. For the sake of comparison, the same figure in the upper part shows the XRD pattern of synthetic mullite free of preferential orientation. Figure 2 shows whiskers having constant thickness, the length being limited by impinging among whiskers continuously growing from the glass phase. The molar ratio between alumina and silica in the whiskers was found, by EDS analysis, to be close to 1.3, with an yttria concentration of less than $0.3 \mathrm{~mol} \%$. Small numbers of almost pure alumina particles are present in the microstructure to compensate for the lower alumina concentration in the whiskers. Because alumina and yttria

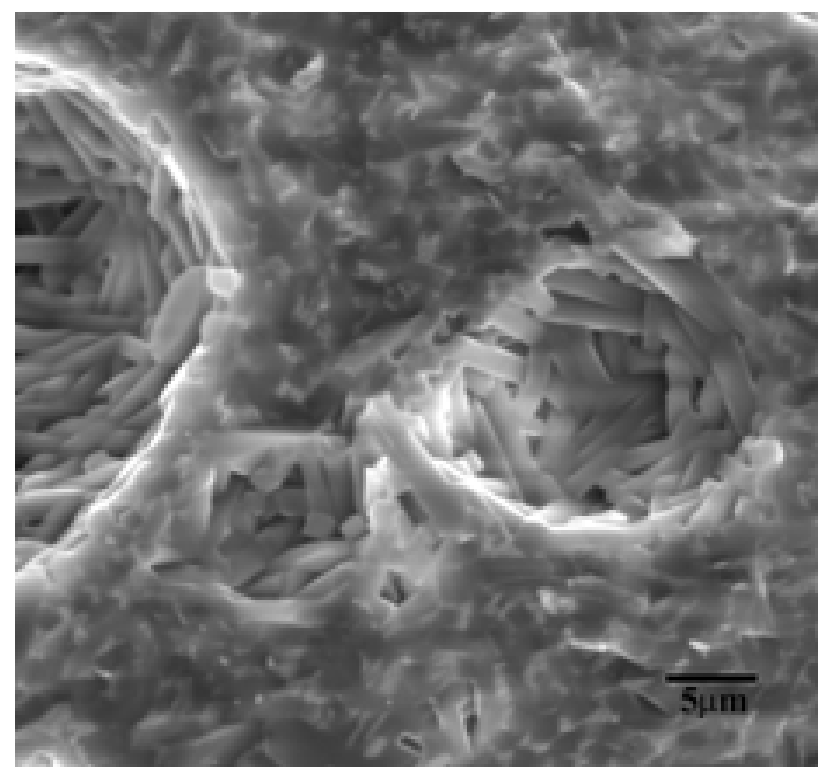

Figure 3. SEM microstructure of internal voids of fracture surface (same pellet of Fig. 2).

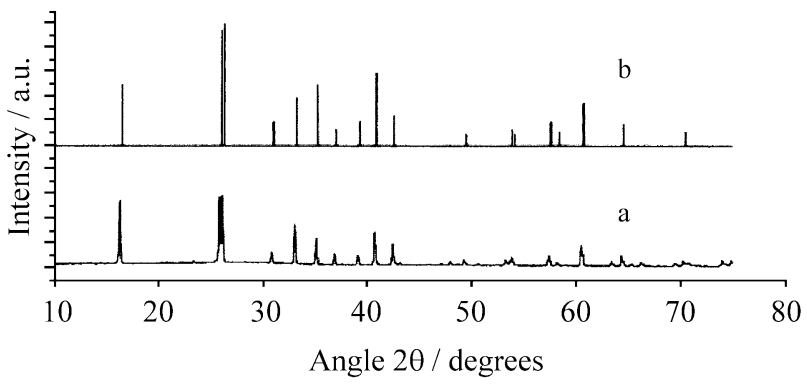

Figure 4. a - XRD pattern of whiskers on the surface of the pellet in Fig. 2; b - mullite diffraction pattern ( file \# 15-776) for comparison. 
concentration are smaller in the whiskers than in the starting powders, whisker growth is followed not only by alumina particles but also by yttria-rich aluminosilicate phases. The EDS analysis of crushed pellet powders shows the presence of these three components; however, the yttria concentration in the glass-like aluminosilicate phase varies from 3.0 to $6.0 \mathrm{~mol} \%$. Also, EDS analyses of the polished pellet surface from which whiskers have grown show a glass phase with an yttria concentration of almost $5.0 \mathrm{~mol} \%$. Powders prepared with the same alumina to silica ratio but with 10.0 mol\% yttria do not produce mullite whiskers but large yttria aluminosilicate crystals with an yttria concentration of approximately $15 \mathrm{~mol} \%$.

Similar results were found for 3.0 mol\% neodimia ${ }^{28}$ and erbia $^{29}$ doped aluminosilicates using high purity aluminum hydroxide (Condea C, Germany) and $99.9 \%$ pure silica (Cerac, USA). In every case, it was found that isostatic pellet pressing is a necessary condition for whisker growth from the $3.0 \mathrm{~mol} \% \mathrm{RE}_{2} \mathrm{O}_{3} 3: 2$ mullite powders.

\section{2b. Addition of pozzolana to cement}

To produce high performance concrete, the HPC of Portland cement, silica does not have to be free of the inorganic compounds that are present in rice hulls. The nature of impurities and their low concentration does not significantly alter the pozzolanic silica reaction. On the other hand, silica must have a small average particle size for this application, a micron or submicron particle size being desirable, and must be reactive to calcium hydroxide. Although the durability and compressive strength of concrete are significantly increased by the addition of silica ${ }^{30}$, the cost of silica for this application is the most important factor. Silica A is highly pozzolanic. Table 1 shows that $85 \%$ of calcium oxide reacted with silica during the accelerated Chapelle test ${ }^{24}$. It is well known that $10 \mathrm{wt} \%$ incorporation of active silica produces maximum effectiveness in enhancing the compressive strength and durability of concrete $^{30}$. To successfully obtain the highest possible efficiency, advanced mixing techniques must be applied to produce concrete with low water content, well dispersed powders and uniform mixtures. The beneficial effect of silica is brought about by its reaction with the excess calcium hydroxide ${ }^{31-33}$ that already exists in Portland cement, especially in the first thirty days of curing. To offer efficient action, silica particle size must be smaller than the water channels and pores in molded concrete and it must also be highly pozzolanic. Figure 5 shows the effect of a 5 wt $\%$ addition of silica A on the compressive strength of blocks made of cement paste as a function of curing time. For the sake of comparison, the results of three other compositions are shown in the same figure, i.e., pure cement, and cement with $5 \%$ and $10 \%$ addition of silica D. It is clearly shown that the addition of silica A is more effective than silica D. An additional curve is also shown,

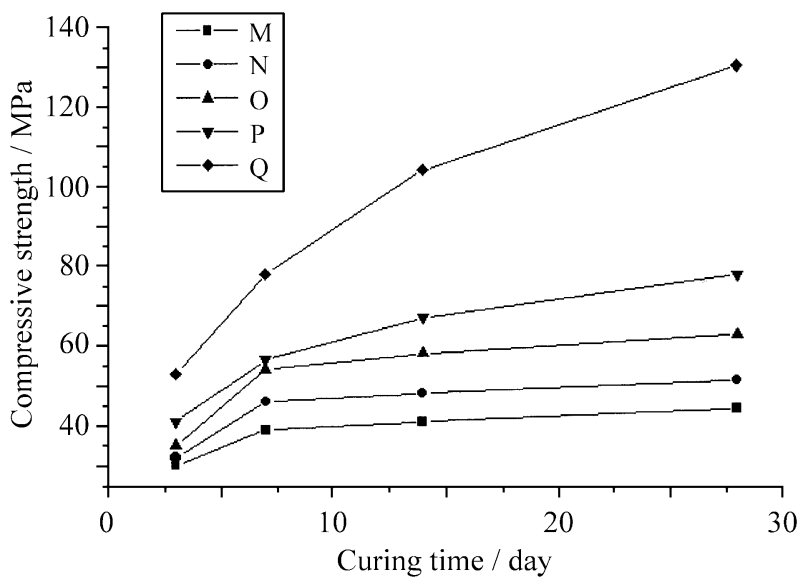

Figure 5. Change of compressive strength due to the addition of silica to cement paste. $\mathrm{M}$ - no addition; $\mathrm{N}$ - 5\% commercial micro silica ; O - 5\% micro silica A; P - 10\% commercial micro silica; Q - 10\% micro silica A (estimated).

representing the estimated increase in compressive strength if $10 \%$ of silica A were added. The effect of adding $10 \%$ of silica A (curve Q, Fig. 5) was estimated as follows: the effective contribution to compressive strength due to the addition of $5 \%$ and $10 \%$ silica D was obtained by subtracting, from each one, the contribution of pure cement; the proportion between them was used to calculate the corresponding $10 \%$ silica A contribution to compressive strength. This estimate assumes a linear relationship among these four quantities that cannot be entirely true. Rice hull ash added to Portland cement produces the opposite effect on the compressive strength of cured cement paste; according to Galal et $a l .{ }^{34}$, rice hull ash decreases the compressive strength. Another very important effect of silica additions is the increased durability of concrete ${ }^{30}$. Reduced porosity in concrete is extremely important in many applications.

The huge volume of rice produced in Brazil every year and the potential use of silica in applications such as irrigation channels, pollution and weather resistant concrete, abrasion resistant floors, slender concrete structures, and many others make research on the extraction of rice hull-derived silica a highly significant enterprise for this country.

Silicon is transported from the roots to the leaves and seed shells by a protein. Protein modification may provide future methods to extract other oxides from the land through plants. It should also be considered that, in future applications, plants may prove to be the source of other oxides and that this same method of extraction may be used.

\section{Conclusions}

Thermal extraction of silica from rice hulls, following the experimental procedures described in this paper, produces high purity materials with high specific surface area. However, the lowest average particle sizes obtained after milling range from 0.6 to 2.0 microns. Purity can be in- 
creased by efficient acid treatment and washing. Particle size may be decreased if a low temperature process is applied to burn cellulose and lignin. It has been demonstrated that silica derived from rice hulls can be used in the preparation of mullite whiskers. The low cost of silica B used as a starting material for the preparation of mullite whiskers may make this innovative process effective ${ }^{28,29}$ to produce whiskers for use in composite materials. It was demonstrated that the concentration of rare earth oxide is much lower in the composition of whiskers than in the starting powders and, therefore, can only remain in the aluminosilicate glass phase. During the acid attack for whisker separation from the glass phase, this phase is dissolved, allowing for reprocessing of the rare earth-rich solution for whisker production.

The high degree of pozzolanic action in silica is well suited for use in high performance concrete and for other applications in construction. Silica extraction costs are very low, involving only simple industrial operations, and the efficiency of silica suffices for these applications. Moreover, silica extraction from rice hulls offers an effective way to reduce pollution caused by burning rice hulls.

\section{Acknowledgments}

The authors would like to express their appreciation to Professor D.G.Pinatti, who so kindly carried out rice hull acid treatments in Lorena, SP, and to Dr. H. Gallo for his work with the electron microscope and Ms. Beatrice Allain for proofreading the grammar and structure. This study was carried out with the financial support of the Brazilian financing agencies FAPESP and FINEP (Pronex).

\section{References}

1. Houston, D.F. "Rice Hulls" p. 301-52. In: Rice Chemistry and Technology, American Association of Cereal Chemists, inc., St Paul, MN, (1972).

2. Yoshida, S.; Ohnishi, Y.; Kitagihi, Soil Science and Plant Nutrition, v. 8, n. 3, p. 1521, 1962.

3. Natajaran, E.; Nordin, A.; Rao, A.N. Biomass \& Energy, v. 14, n. $5-6$, p. $533,1998$.

4. Harima, E. "Stabilization of Phase and Preparation of $\alpha$ Phase of Crystobalite from the Residue of Rice Hull Burning”, MS Thesis, University of São Paulo - São Carlos Campus, march 1997.

5.Jin, Z.C.; Jia, L.Y.; Jia, X.C. Cellulose Chemistry and Technology, v. 26, p. 345, 1992.

6. Hanna, S.B.; Farag, L.M.; Mansour N.A.L. "Pyrolysis and Combustion of Treated and Untreated Rice Hulls", Thermochimica Acta, v. 81, p. 77, 1984.

7. Lee, J.B.; Cutler, I.B. Am. Ceram. Soc. Bull., v. 54, n. 2, p. 195, 1975.

8. Krishnarao, R.V.J. Eur. Ceram. Soc., v. 12, p. 395, 1993.
9. Rahman I.A.; Riley F.L.J. Eur. Ceram. Soc., v. 5, p. 11, 1989.

10. Martinelli, J.R.; Bressiani, A.H.A.; Bonetti, M.C. Anais $10^{\circ}$ CBECIMAT, Águas de Lindoia, SP, p. 126, dezembro/1992.

11. Martinelli, J.R.; Bressiani A.H.A. Anais $9^{\circ}$ CBECIMAT, Águas de São Pedro, SP, p. 514, dezembro/1990.

12. Yoshida, S.; Ohnishi, Y.; Kitaghisi, K. Soil Science and Plant Nutrition, v. 8, n. 1, p. 29, 1962.

13. Sterling, C. Amer. J. Bot., v. 54, n. 7, p. 840, 1967.

14. Lanning, F.C. J. Agr. Chem., v. 11, n. 5, p. 435, 1963.

15. Sheng, L.L.; Chin, H.H. J. Chinese Chemical Soc. (Taiwan), v. 6, p. 141, 1961.

16. James, J.; Subba Rao, M. Thermochimica Acta, v. 97, p. 329, 1986.

17. Bartha, P.; Huppertz, E.A. Proc. Rice By-products Conf., Valencia, Spain, p. 89, 1974.

18. Hamad, M.A.; Kattab, I.A. Thermochimica Acta, v. 48, p. 343,1981 .

19. Amick, J.A. J. Electrochem. Soc., v. 129, n. 4, p. 864, 1982.

20. James, J.; Subba Rao, M. Am. Ceram. Soc. Bull., v. 65, n. 8, p. 1177, 1986.

21. Real, C.; Alcalá, M.D.; Criado, J.M. J. Am. Ceram. Soc., v. 79, n. 8, p. 2012, 1996.

22. Yamamoto, J.; de Souza, M.F. Cerâmica, v. 45, n. 291, p. 34, 1999.

23. Chapelle J. Revue des Materiaux des Construction, v. 512, p. 136, 1958.

24. Raverdy, M.; Brivot, F.; Paillere, A.M.; Dron, R. $7^{e}$ Congrès International de la Chimie des Ciments, Paris, v. 3, IV-36-41, 1980.

25. D'Angelis, D.F. Joint Project on Rice Hull Microbiological Attack, Dep. Of Biochemistry and Microbiology, Rio Claro, UNESP, Rio Claro, SP, Brazil.

26. de Souza M.F.; Batista P.S.; Liborio, J.B.L. Processo de extração da sílica contida na casca e na planta do arroz., Brazilian Patent, submitted.

27. Aksay, I.A.; Dabbs, D.M.; Sarikaya, M. J. Am. Ceram. Soc., v. 74, n. 10, p. 2343, 1991.

28. de Souza, M.F.; Regiani, I.; de Souza, D.P.F. "Mullite Whiskers from Rare Earth Oxide Doped Aluminosilicate Glasses", to be published in J. Mater. Sci. Lett.

29. de Souza, M.F.; Yamamoto, J.; Regiani, I.; de Souza, D.P.F. "Mullite Whiskers Grown From Erbia-Doped Aluminum Hydroxide-Silica-Gel" to be published in $J$. Am. Ceram. Soc.

30. Ollivier, J.P.; Durability of Concrete, Class Notes, Escola Politécnica - USP, Brazil, may, 1998.

31. Double, D.D.; Hellawell, A. Nature, v. 261, p. 486, 1976. 32. Double, D.D.; Hellawell, A. Sci. Am., v. 237 p. 82, 1977.

33. Viehland, D.; Li, J.F.; Yuan, L.J.; Xu, Z. J. Am. Ceram. Soc., v. 79, n. 71, p. 1731, 1996.

34. Galal, A.F.; Taha, A.S.; Helmy, I.M.; El-Didamony, H. Silicates Industriels n. 1-2, p. 55, 1990. 